\title{
Are school textbooks misleading?
}

\author{
Matthew T. Wood ${ }^{1} \cdot$ Sophie A. Wood ${ }^{1} \cdot$ Melanie C. Corbett ${ }^{2,3}$
}

Received: 25 July 2019 / Accepted: 8 August 2019 / Published online: 25 October 2019

(c) The Royal College of Ophthalmologists 2019

\section{Introduction}

Teaching in schools aims not only to educate people for future employment, but also for life. There is a vast quantity of material to cover so they have to achieve simplicity without compromising accuracy. During work experience, whilst discussing a patient with a severe chemical injury to the ocular surface, it became apparent that the conjunctiva should not be continuous over the cornea. This conflicted with prior learning from school textbooks [1]. This study investigated the importance of this error, and whether it should be corrected.

\section{Methods}

Seven biology textbooks for GCSE and A level were assessed for the accuracy of conjunctival anatomy in diagrams and text. Sixty-five pupils, teachers, and medical professionals completed a questionnaire to obtain opinions on the importance of the error and their reasoning. The publishers were informed of the error by comparing their diagram with one from a medical text and supporting histological evidence (Fig. 1). They were invited to comment.

\section{Results and discussion}

In all seven textbooks, the diagram incorrectly portrayed the conjunctiva as covering the whole ocular surface including the cornea (Fig. 1). The anatomy was also described incorrectly in two of the three books mentioning it in the text.

\footnotetext{
Melanie C. Corbett

education@rcophth.ac.uk

Kingston Grammar School, London, UK

Imperial College NHS Trust, London, UK

Royal College of Ophthalmologists, London, UK
}

Accurate teaching of conjunctival anatomy was considered to be of major or moderate importance for pupils $(80 \%)$, teachers $(94 \%)$, patients $(88 \%)$, and medical professionals (99\%) (Fig. 2). Reasons given ranged from the need for accuracy without simplification for pupils to the value of correct information for potential patients and future healthcare workers.

A common theme among questionnaire answers from several groups was the conflict between accuracy and simplicity. However, several pupils suggested that there was "no need for simplification" as "the correct information is easy to understand." They were also concerned that this meant that there may be "other inaccuracies in textbooks" and that subsequently teachers "could lose credibility." They recognized that "school education is the groundwork for future learning" and "the basis of further study." However, teachers were most concerned that their teaching "matched the exam specification."

Potential patients might have difficulty "understanding their eye condition," or "complying with treatment." Correct knowledge could help them "communicate with their doctor" and "give informed consent." Patients who
A

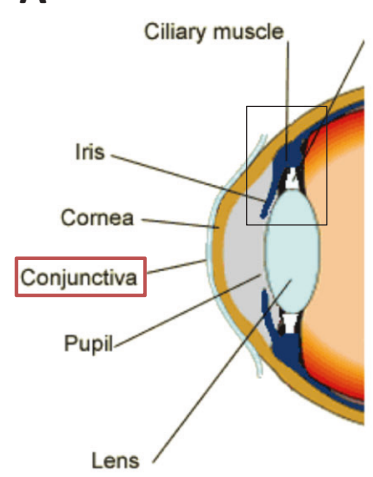

B

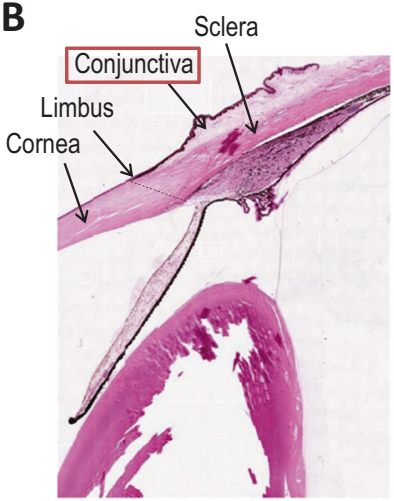

Fig. 1 Conjunctival anatomy. a Incorrectly depicted as overlying the cornea in a drawing from a school textbook. b Correctly abutting the corneal epithelium at the limbus and extending peripherally, as demonstrated histologically. The box shows the area of the drawing represented histologically 
Fig. 2 Histogram showing relative importance of school textbooks containing accurate information for pupils, teachers, patients, and medical professionals. Each column shows the breakdown of responses by the different groups

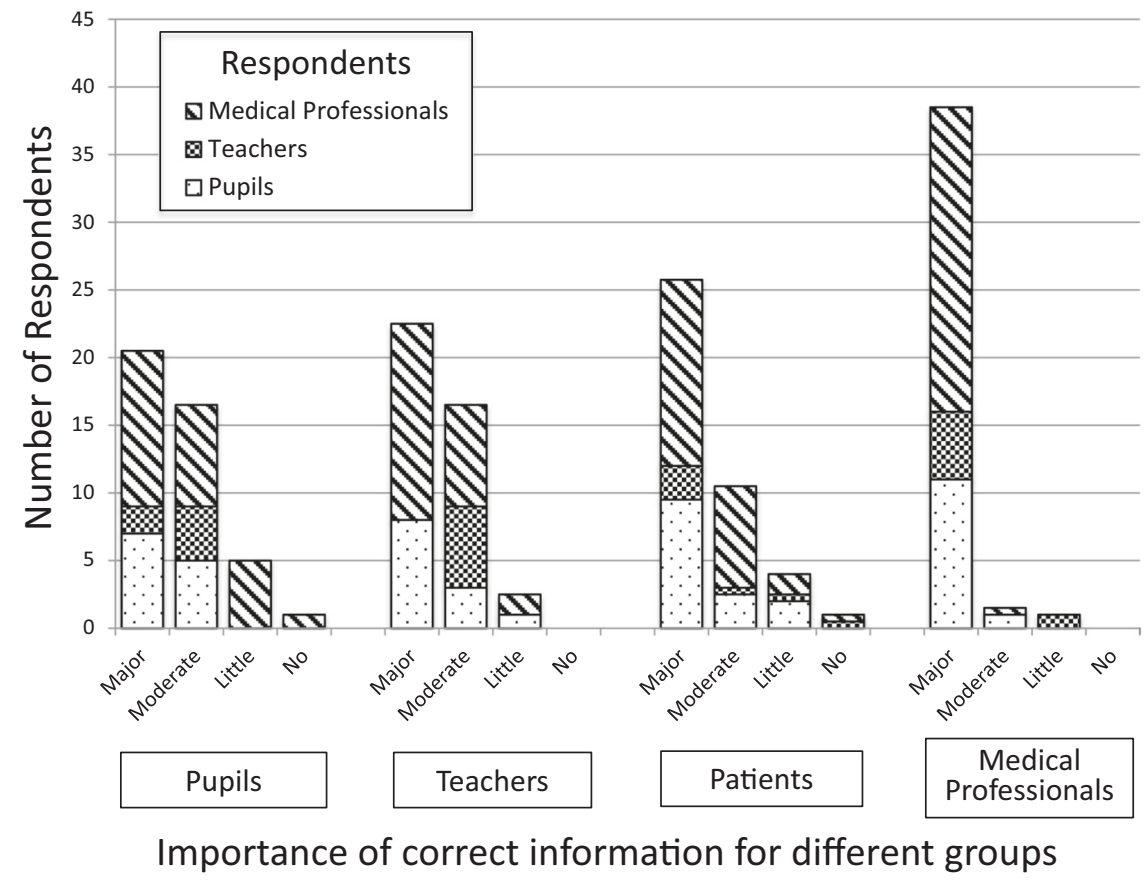

correctly "self-diagnose conjunctivitis" can "seek over the counter treatment."

Future healthcare students may have "difficulty with the conflict with prior learning" and "unlearning prior knowledge." However, it was expected that they would "relearn the correct information" for their future careers.

One publishing house had responsibility for multiple texts. They said that the information provided was "incredibly helpful," and agreed to correct their next print runs [2]. They informed relevant examination boards, stimulating a discussion about how much detail about the eye was required in school textbooks. They requested our views as informed parties.

\section{Conclusion}

The majority of school textbooks incorrectly depicted the conjunctiva as covering the cornea. By providing histological evidence of the error, and user opinion of its importance, it was possible to influence publishers and examination boards about the value of teaching accurately about the eye.

\section{Compliance with ethical standards}

Conflict of interest The authors declare that they have no conflict of interest.

Publisher's note Springer Nature remains neutral with regard to jurisdictional claims in published maps and institutional affiliations.

\section{References}

1. Bradfield P, Porter S. Edexcel IGCSE biology (student book). London, UK: Pearson Education Limited; 2009. p. 272.

2. Hewish A. Personal communication. Oxford, UK: Oxford University Press; 2019. 